\title{
Osteoporosis Complicating Some Inborn or Acquired Diseases
}

\author{
I. ZOFKOVA ${ }^{1}$, P. NEMCIKOVA ${ }^{2}$ \\ ${ }^{1}$ Institute of Endocrinology, Prague, Czech Republic, ${ }^{2}$ Department of Nuclear Medicine, \\ České Budějovice Hospital, Czech Republic
}

Received July 13, 2018

Accepted September 13, 2018

\begin{abstract}
Summary
Osteoporosis in chronic diseases is very frequent and pathogenetically varied. It complicates the course of the underlying disease by the occurrence of fractures, which aggravate the quality of life and increase the mortality of patients from the underlying disease. The secondary deterioration of bone quality in chronic diseases, such as diabetes of type 1 and type 2 and/or other endocrine and metabolic disorders, as well as inflammatory diseases, including rheumatoid arthritis - are mostly associated with structural changes to collagen, altered bone turnover, increased cortical porosity and damage to the trabecular and cortical microarchitecture. Mechanisms of development of osteoporosis in some inborn or acquired disorders are discussed.
\end{abstract}

\section{Key words}

Osteoporosis • Celiac disease • Phenylketonuria • Crohn disease

- Rheumatoid arthritis • Hyperthyreosis

\section{Corresponding author}

I. Zofkova, Institute of Endocrinology, Národní 8, 11694 Prague, Czech Republic. E-mail: izofkova@upcmail.cz

\section{Introduction}

It is known that the low bone density and high bone fragility increase risk of fractures and often complicate many endocrinopathies and metabolic disorders (primary hyperparathyroidism, hyperthyroidism, hypercortisolism, diabetes mellitus of type one and type two, growth hormone deficiency, diabetes insipidus and others). Osteoporosis is also associated with chronic diseases of a non-hormonal nature. Strong detrimental effects on the skeleton have been recorded from chronic inflammatory diseases, such as rheumatoid arthritis, psoriasis, ankylosing spondylitis, pemphigus vulgaris, systemic lupus erythematosus (Briot et al. 2017, Barake et al. 2017). The compensation and treatment of these diseases will slow the loss of bone mass and may reduce the risk of fracture. Diseases, which deteriorate the skeleton can outbreak in childhood or they are acquired during adulthood. The article discusses the pathogenesis of osteoporosis complicating selected internal disorders, including cirrhosis of the liver, chronic hepatitis and chronic obstructive pulmonary disease. Straub et al. (2015) characterize this osteoporosis as an ,accident of inflammation“. Recent data and literature search were obtained in PubMed.

\section{Inborn metabolic diseases associated with bone deterioration}

\section{Celiac disease}

Celiac disease (gluten-sensitive enteropathy, non-tropical sprue) affects approximately $1 \%$ of the population in Europe and the USA (Hernandez and Green 2006). It is to be expected, with the availability of modern serological methods performed in the risk groups, that there is going to be an increase in the number of patients with an adult variant of celiac disease. It is essentially a genetically determined autoimmune hypersensitivity of the intestinal cell to gluten. It affects the mucous membrane of the small intestine by inflammation, induces villous atrophy and widening or hyperplasia of the crypt, which leads to nutrient malabsorption (Briani et al. 2008). Histological changes 
in the intestinal mucosa usually occur with a daily dose of gluten exceeding $10 \mathrm{mg}$ (Akobeng and Thomas 2008).

\section{Genetics of celiac disease}

It was observed that celiac disease is often bound to the class II HLA system (chromosome 6p21). In around $50 \%$ of Danish population were HLA DQ2/DQ8 positive and therefore potentially risky for celiac disease (Karhus et al. 2018). Similarly, approximately $90 \%$ of celiac patients have a DQ2 or DQ8 haplotype, as compared with only $40 \%$ of general population (McAllister et al. 2018). The polymorphism beta57 in the HLA-DQ8 gene amplifies the T-cell activation and it is associated with an increased sensitivity of the body to gluten. Symptomatic carriers of the HLA-DQB1*02 genotype have high titers of antibodies against transglutaminase I. Moreover, the HLA system may also be associated with some extraintestinal autoimmune diseases that occur more frequently with celiac disease than in unaffected populations. Children suffering from both celiac disease and type 1 diabetes are more likely carriers of the HLA-DQ 2/8 gene than children with isolated celiac disease or healthy children (Lewandowska et al. 2018). The genes common to celiac disease and type 1 diabetes were identified at chromosomes $1 \mathrm{q} 31$ and 6q25. Other risk genes for both diseases were localized at chromosomes 3p21, 18p11, 2q33 and 12q24 (Verdu and Danska 2018). The MAG12 gene, which is responsible for intestinal damage in celiac disease, was also identified with the method GWAS (Genome-wide Association Study), which could identify other genes common to celiac disease and associated autoimmune disease and could thus contribute to the early diagnosis of these diseases (Abadie et al. 2011). Moreover, recently epigenetics and microbiota appeared to be further potent factors, affecting disease manifestation and targeting therapeutic procedures (Dieli-Crimi et al. 2015).

The first manifestations of the disease can occur in childhood, more often in early adulthood in diarrhea and malabsorption syndrome, in slowing growth, loss of weight, and children's total lag behind their peers. There are increasing cases being diagnosed in adulthood or even over 60 years of age, when classical manifestations are not fully expressed, and malabsorption syndrome and increased bone loss are mostly attributed to the physiological aging. In adulthood, the manifestations of the accompanying diseases - most commonly autoimmune diseases (diabetes mellitus of type one, chronic thyroiditis, connective tissue disease) often highlight celiac disease. The prevalence of seropositive celiac disease is about $28 \%$ in general population (Juneau et al. 2018). Therefore, screening is recommended for celiac disease in all patients with autoimmune disorder. In celiac disease, a higher incidence of other extraintestinal diseases (T-cell lymphoma, herpetiform dermatitis, neuropathy, Sjögren's syndrome, male infertility, or hypochromic hyposideremic anemia) has been observed. Extremely serious complications of celiac disease include osteoporosis and osteomalacia with subsequent fractures. Decreased bone density was observed in $50 \%$ of children with histologically verified celiac disease. The low peak bone mass achieved in adolescence is the cause of low traumatic fractures in adulthood (Abadie et al. 2011). In any way, quality of life is deteriorated in all celiac patients (Martinez-Martinez et al. 2018).

\section{Mechanisms of the development of osteoporosis in celiac disease}

The basic causes of the accelerated loss of bone mass are chronic inflammation and malabsorption (Bianchi and Bardella 2008). Inflammatory cytokines IL- $1 \alpha$, IL- $1 \beta$ and TNF- $\alpha$ produced by the intestinal mucosa activate the bone resorption and accelerate the loss of bone mass. The relationship of cytokines to the skeleton is also probably determined genetically. Moreover, it is also interesting to note the evidence of a higher incidence of osteoporosis in other healthy relatives of patients with celiac disease, who had higher IL-1 $\beta$ levels (Stazi et al. 2008). The inflammationactivated bone resorption is further stimulated by overproduction of parathyroid hormone, which is the result of hypocalcemia caused by insensitivity of inflammatory intestinal mucosa to $1,25(\mathrm{OH})_{2}$ vitamin D and by malabsorption of calcium and vitamin $\mathrm{D}$ (Cashman 2008). Other factors may also contribute to acceleration of bone loss in patients with celiac disease, such as a history of multiple pregnancies or prolonged hypoestrinism and hyperprolactinemia in men. Individuals simultaneously suffering from a deficit of somatotropin or sarcopenia - the factors that damage the stability of bone mass - also have a higher risk of osteoporosis. Also, patients who are on long-term medications that activate the axis RANK/RANKL/ osteoprotegerin, such as glucocorticoids, carry an increased risk. 


\section{Laboratory detection of gluten-sensitive enteropathy}

From the point of view of the prevention of osteoporosis and other complications of celiac disease, the early detection of the disease is important, using gliadin, transglutaminase and endomysial IGA antibodies. Determination of antibodies is indicated, for example, in patients with unexplainable secondary hyperparathyroidism, or in premenopausal women with osteoporosis not responding to conventional antiresorptive therapy. The final diagnosis of celiac disease is reliably confirmed by an intestinal biopsy. The expensive determination of genetic markers to identify patients at risk of osteoporosis is still only theoretical.

Prevention and treatment for bone disorder in celiac disease

A basic step in the prevention of osteoporosis is the treatment of celiac disease, which consists in the timely introduction of a gluten-free diet. This alone often leads to the normalization of levels of $25(\mathrm{OH})$ vitamin D and parathyroid hormone, and then to an increase in bone density. A gluten-free diet is also recommended for children in long latency. If there is not an adequate rise in vitamin D levels, calcium and cholecalciferol substitution is indicated. Prospects for the future are specific proteases, which reduce the toxicity of gluten, or the inhibitory immunomodulator recombinant alpha-gliadin. Currently, the effect of larazotide (AT-1001) is being examined (Khaleghi et al. 2016). This synthetic peptide works as a permeability regulator, which (under condition of normal calcium-phosphate homeostasis) regulates the function of the intestinal epithelial cells in celiac disease. The effect is conditioned by more severe loss of bone mass, non-specific anti-resorptive treatment with bisphosphonates or the monoclonal antibody against RANK should be considered (Miller 2009).

Altogether, celiac disease is not a rare autoimmune disorder affecting the intestinal mucosa, which occurs in genetically disposed individuals. It is often associated with other extra-intestinal diseases predominantly of an autoimmune nature. The fundamental mechanisms by which celiac disease damages the bone are inflammation and malabsorption. The most serious consequence for the integrity of the skeleton is the disease when it manifests in childhood, when it causes insufficient development of the peak bone mass. However, even ,mute" forms of disease in adults and older persons can accelerate the physiological loss of bone mass and may lead to the formation of secondary osteoporosis and/or osteomalacia. The early detection of the disease and its objective treatment can prevent the development of pathological fractures. However, it is necessary to bear in mind that laboratory tests on celiac disease have a low specificity and sensitivity, therefore their practical applicability is limited.

\section{Phenylketonuria (PKU)}

PKU is a hereditary, autosomal recessive metabolic disorder caused by mutation in the PAH gene for phenylalanine hydroxylase. Although it is typically diagnosed in children, it may also deteriorate the adult skeleton (Sumánszki et al. 2017). In the liver, in the presence of a tetrahydrobiopterin cofactor, the phenylalanine hydroxylase degrades the amino acid phenylalanine to 5-hydroxytryptophan (serotonin). The mutation in some of the 13 exons, in the intron or the promoter region of the PAH gene (548 mutations in total have been described) or in the tetrahydrobiopterin gene (1-2\% of cases) leads to a slowdown in the metabolism of phenylalanine to 5-hydroxytryptophan. The phenylalanine concentration in blood and tissues is abnormally high, while the level of 5-hydroxytryptamine is low. The effect of this deviation is the attenuation of the synthesis of neurotransmitters (serotonin and dopamine), which leads to severe brain damage that dominates in this disease. Some mutations in the gene may cause only a mild form of phenylketonuria, when the level of phenylalanine in the blood just slightly exceeds the upper limit of the standard (normal range 50-110 $\mu \mathrm{mol} / \mathrm{l})$.

\section{Hyperphenylalaninemia and the skeleton}

Although PKU is mostly diagnosed in children, a study on a small number of probands showed that osteopenia in phenylketonuric men and women aged 20-30 was confirmed in $39 \%$ of cases, osteoporosis in $6.5 \%$ (Modan-Moses et al. 2007). The primary cause of the bone metabolic disorder in phenylketonuria is the direct effect of phenylalanine, which will accelerate the conversion of mononuclears to osteoclasts. In the experimental study, however, the association of phenylketonuria and osteopenia was not clearly confirmed. Although the risk of osteopenia in phenylketonuria is not high, this disease can significantly slow down the development of bone mass in children with delayed puberty, with an inadequacy of growth factors and active metabolites of vitamin $\mathrm{D}$, or an imbalance in soft tissue composition. Because the 
peripheral quantitative computer tomography (pQCT) in phenylketonurics showed a decreased value in the density of the trabecular bone (even at normal DXA values), it can be assumed that phenylketonurics have primarily reduced bone quality and strength. Bone metabolism with phenylketonuria is likely negatively influenced also by the deficiency of 5-hydroxytryptamine, which alone has an osteoanabolic effect. Furthermore, pQCT is able to analyze not only deterioration of bone metabolism, but also neuromuscular abnormalities (Choukair et al. 2017). Thus, the most reliable information on the function of skeletal damage in phenylketonuria is provided by pQCT.

In pediatric patients, the 17 quantitative ultrasound (QUS) can also be used, which shows the low values of mineralization and cortical thickness in suspected cases. Z-score SOS (speed of sound) and broad-band ultrasound attenuation (BUA) negatively correlated with the plasma level of phenylalanine. The method is also suitable for long-term monitoring of the state of the skeleton. The current bone remodeling activity can be monitored by measuring bone formation and bone resorption markers, always with respect to the age of the patient.

The basis of the treatment is the consistent control of phenylalaninemia, which is based on the strict restriction of natural proteins containing phenylalanine and on the supplementation of neutral synthetic acids, glycomacropeptide and calcium. The decrease in phenylalanine levels may be achieved by administering tetrahydrobiopterin (Van Spronsen and Enns 2010). However, inadequate amino acid intake in patients with PKU may increase the detrimental effects on the skeleton. The impact of the suppressed production of serotonin, which itself, under physiological conditions, activates new bone formation, needs to be analyzed.

The early detection of phenylketonuria has paramount importance, and if it is carried out in the context of screening for congenital diseases, it can prevent not only severe mental retardation, but also poor skeletal development in children and subsequent osteoporosis in adulthood (van Wegberg et al. 2017, Sumaily and Mujamammi 2017). The aim of the research is also the study of the bone metabolism focused on PKU in adult and elderly suspected populations. Apart from the substitution of phenylalanine hydroxylase, that would restore enzyme activity, gene therapy holds promise for the future. Thus, untreated phenylketonuria may cause the insufficient development or the accelerated loss of the bone mass and therefore also the increased risk of fractures. Pathogenesis of this form of osteopenia/ osteoporosis has a complex nature (first the direct effect of hyperphenylalaninemia and further nutritional deficiency, mainly inadequate amino acid intake) (Hochuli et al. 2017).

\section{Further inflammatory gatrointestinal diseases, complicated by osteoporosis}

\section{Crohn disease and ulcerative colitis}

$36 \%$ of patients with Crohn disease and $32 \%$ with ulcerative colitis showed osteopenia, and $15 \%$ with Crohn disease and $7 \%$ with ulcerarive colitis showed osteoporosis. Due to the overexpression of inflammation cytokines, such as IL13, IL-1 $\beta$ and IL4, bone resorption markedly increases in inflammatory bone diseases (IBD), although bone formation is unchanged, or inhibited, partly as a result of treatment with glucocorticoids and malnutrition (Krela-Kažmierzak et al. 2016). In steroidfree bowel inflammation in remission, Bastos et al. (2017) still found low bone mass with Z-score -2.0 at L1-L4, which indicates that factor(s) responsible for bone loss in active IBD may have a long-lasting effect on the skeleton. Osteopenia/osteoporosis is caused by inflammation alone together with malnutrition and glucocorticoid treatment. To identify bone microarchitecture in patients with IBD, peripheral quantitative computer tomography (pQCT) is recommended, which usually correlates with the severity of IBD (Maratova et al. 2017).

Besides inflammatory gastrointestinal diseases, the skeleton is deteriorated by gastrectomy status, short bowel syndrome or state of achlorhydria (e.g. induced by the treatment with proton pump derivatives) (KrelaKazmierczak et al. 2015). Serious metabolic disease complicated by osteoporosis is also inborn or secondaryacquired hypolactasia leading to milk intolerance, increase in bone turnover, reduced BMD and osteoporotic fractures. This mostly autosomal recessive disease, which may have a severe impact on calcium and vitamin D homeostasis, may be associated with TC-13910 polymorphism. Deleterious effect of milk intolerance on BMD was described in a population of Northern Europe (Kull et al. 2009).

New prospects in the therapy of IBD consist in biological therapy, such as monoclonal antibodies against TNF or special small molecules, which easily penetrate into inflammation tissues (reviewed by Douda 2018). 


\section{Rheumatoid arthritis}

The current cause of osteopenia/osteoporosis is inflammatory joint disease - especially rheumatoid arthritis (RA), but also other rheumatoid diseases, such as lupus erythematosus, systemic sclerosis, ankylosing spondylitis or psoriasis, which all are characterized by inflammation and limited mobility leading to irreversible structural damage of the affected joints and the skeleton. A specific association develops between autoimmunity and the skeleton, in which antibodies recognizing citrullinated proteins and rheumatoid factor become powerful osteoclast activators triggering bone loss (Schett 2017). The hyperactivity of antibodies and proinflammatory cytokines (IL-1, IL-6 and IL-17) in RA stimulates above all the synthesis of RANKL in chondrocytes, which results in periarticular activation of bone resorbing osteoclasts (Braun and Schett 2012). A typical radiological finding is periarticular bone thinning with characteristic marginal erosions, whose repair is slowed down as a result of diminished bone formation. In RA, the direct effect of inflammation on the bone is enhanced by glucocorticoid therapy, malnutrition, physical inactivity and muscle atrophy. Continuing hyperactivity of bone resorption induces the acceleration of cortical bone loss, the expansion of the endosteal circuit and the reduction of bone strength. At this time, bone deterioration has not only a focal, but also a systemic character due to accelerated bone loss, but also microstructure damage. Children with RA, mainly those with late onset of puberty have a poor development of peak bone mass (Burnham 2012). Among adults, there is most risk of osteoporotic fracture in postmenopausal women and patients with other severe diseases (e.g. cardiacs, patients with obstructive pulmonary disease and diabetics) and/or those living in harmful environment (smokers, alcoholics). Genetic analysis holds some promise for the future, as it will allow the prediction of the risk of osteoporosis in RA. A study conducted in 350 women (200 diagnosed with RA) found an association between bone density of the hip and variations in genes for VDR (polymorphism BsmI) and OPG (polymorphism A163G). Female carriers of the $\mathrm{G}$ allele (in the $\mathrm{A} 163 \mathrm{G}$ polymorphism) also have simultaneously a significantly higher risk of RA and osteoporosis (Hussien et al. 2013). The similar association was also described in white population by Mencej-Bedrac et al. (2009).

The basis of prevention and treatment of osteoporosis complicating RA is the suppression of inflammation, supplementation of vitamin D, calcium and menatetrenone (vitamin K2). According to the European guidelines for osteoporosis from 2009, in postmenopausal women, who are receiving glucocorticoids at doses above $7.5 \mathrm{mg}$ prednisone daily for more than three months and who are achieving a DXA score below -2.0, anti-resorptive medication at the start of treatment with glucocorticoids is recommended. Teriparatide shows osteoanabolic effect, which could slow down the development of bone erosions in these patients. Promise for the future holds biological therapy with anti RANKL antibodydenosumab. Both these treatment have only transitory effects and thus the treatment should be followed by the course of further antiresorptive therapy.

The loss of bone mass is also observed in autoimmune diseases, such as systemic lupus erythematosus. Osteoporosis in this disease is related to the detrimental effect of lupus itself and to frequent vitamin D deficiency. A strong causal effect on the skeleton is attributed to long-term glucocorticoid treatment (Edens and Robinson 2015). In patients with some other autoimmune diseases, such as systemic sclerosis, vitamin D deficiency plays an essential role in the development of the disease and osteoporosis (Szamosi et al. 2017).

\section{Endocrine and metabolic diseases associated with accelerated bone loss}

\section{Hyperthyroidism}

A number of endocrine disorders are complicated by osteopenia/osteoporosis. Bone deterioration is very serious in chronic hyperthyroidism, and, in particular, in the life-long treatment with high (suppressive) doses of thyroid hormones. Triiodothyronine at physiological concentrations acts directly on the skeleton via specific receptors on osteoblasts. It stimulates osteoblastic activity and it has a key importance for the linear growth and development of peak bone mass in children. In adulthood, thyroid hormones promote the mineralization of bone and improve its quality. In euthyroid postmenopausal women, the tyrosine concentration positively correlated with the number of progenitor bone cells in circulation. Belsing et al. (2010) recorded low bone density in the femoral and lumbar spine in premenopausal women with Graves' disease. When euthyreosis was obtained, the bone density normalized, but after 18 months of discontinuation of 
thyrostatic action, the BMD decreased again in negative correlation with serum thyroxin levels. Bone loss and decline of bone strength in hyperthyroidism are induced by an increase in IL- 6 and cathepsin K and partly via the physiological decrease in TSH levels, as the later hormone is a relatively strong bone anabolics (Mysliwiec et al. 2011, Zhang et al. 2014). The correlation study in euthyroid postmenopausal women noted the significant reciprocal relationship between serum TSH levels and some parameters of osteoresorption (Zofkova and Hill 2008). Furthermore, TSH in rats and under certain experimental condition also prevents bone resorption (Dumic-Cule et al. 2014). As osteoporosis induced by hyperthyroidism is not only a problem of postmenopausal women, the aim of the treatment is to achieve permanent remission of hyperthyroidism independently of the age or gender. The skeletons of patients with thyroid carcinoma, who are treated with high doses of thyroid hormones over a long period, are extremely endangered. The bone response is proportional to the dose of hormone, particularly in women with hypoestrinism, chronic inflammatory diseases, smokers and alcoholics. Treatment with thyrostatic pharmaceuticals slows the loss of bone mass or accelerates its growth in children. The treatment of severe osteoporosis in hyperthyroid patients - except thyreostatics - is based on the administration of anti-resorptive drugs. Inhibitors of cathepsin $\mathrm{K}$ are a future prospect.

\section{Further weighty endocrine and/or metabolic diseases threatening the skeleton}

\section{Diabetes mellitus}

Type 1 and the type 2 diabetics are very often affected by osteoporotic fractures, which reduce the quality of life of the patients, similar to other major diabetic complications (Vokó et al. 2017). The pathogenesis of skeletal damage in diabetics differs in individual patients, mainly depending on the type of disease. While type 1 diabetes, the bone density value is markedly decreased, diabetics with type 2 have impaired bone quality, even at normal or elevated bone density. Botushanov and Orbetzova (2009) showed the relative risk of hip fracture in women with type 1 diabetes to be higher (RR: 8.9) than for women with type 2 diabetes (RR: 2.0). Therefore, the fracture risk is higher for type 1 diabetics.

The pathogenesis of osteoporosis in diabetes has a complex nature and it is partly outlined by Montagnani et al. (2011). Hyperglycemia itself has a toxic effect on osteoblasts, as it reduces their sensitivity to $1.25(\mathrm{OH})_{2} \mathrm{D}$. In addition, it stimulates the proadipocytic transcription factor PPAR $\gamma$, thus it activates adipogenesis to the detriment of osteogenesis. The bone quality in diabetics also damages the storage of glycosylation products and pathological cross-bridges in collagen, which is related to oxidative stress. Decreased bone formation is the crucial mechanism leading to reduced bone mass in diabetics. Bone metabolism is also negatively influenced by a low level of insulin, IGF-1 and IGF-2, high levels of proinflammatory cytokines, as well as by hyperinsulinemia in type 2 diabetes. The negative effect of oxidative stress and increased homocysteine levels on the skeleton in diabetics is also discussed (Tariq et al. 2018, Samadi et al. 2018). Adipokines inflammatory factors, TNF- $\alpha$, interleukin- 6 and CRP in patients with complicating osteoporosis were significantly higher than in those without osteoporosis (Chen et al. 2017). Thus, increased inflammatory response, an abnormal lipid spectrum in the blood and a change in adipokines increase the risk of osteoporosis in patients with diabetes mellitus. The bone quality in diabetes could also be endangered by prolonged diabetic neuropathy, microangiopathy and hypercalciuria (Montagnani et al. 2011). In type 2 diabetes, there is also speculation about the detrimental effect of sclerostin, which inhibits Wnt/ $\beta$-catenin signaling, and thus the function of osteoblasts (Graat-Verboom et al. 2012). Influence of the hormones of the skeleton was reviewed in detail by Zofkova (2015). Another negative factor is treatment with some antidiabetics. While metformin has a beneficial effect on the skeleton (it reduces the deposition of glycosylation products in bone), the thiazolidinediones have a negative effect because they direct to the differentiation of the mesenchymal progenitor cell in favor of adipogenesis. The final products of glycation (AGE) and pentosidine become the candidate markers of fracture risk in diabetics. Prevention of fractures in diabetics is based on strict glycemic control, supplementation of calcium and vitamin D, and permanent monitoring of the bone density. In cases of osteoporosis, antiresorptive therapy is mostly indicated. Besides teriparatide, promising for the future are derivatives of incretin-glycogen like peptide (GLP-1) and glucose-dependent insulinotropic polypeptide (GIP), which control glycemia and directly activate the process of new bone formation. 


\section{Protoporphyria}

Osteoporosis or osteopenia are frequent in patients with erythropoietic protoporphyria (metabolic disease characterized by increased photosensitivity due to accumulation of protoporphyrin IX). Vitamin D deficiency and weight-bearing exercise correlates with low BMD was observed in these patients (Biewenga et al. 2017). Thus, pathogenesis of bone deterioration in protoporphyria is most probably complex.

\section{Hyponatremia}

Hyponatremic patients showed a markedly higher rate of hip fractures. Mild long-term chronic hyponatremia (89 days duration) is independently associated with hip fracture risk in older humans (Ayus et al. 2016). However, correction of hyponatremia did not lead to a decline in hip fractures. The causal association between hyponatremia and low bone mass remains questionable.

\section{Unusual effects of endogenous uric acid on the skeleton}

Interestingly, uric acid has a positive effect on bone metabolism in obese subjects, in whom the serum osteocalcin directly and independently correlates with serum uric acid. Some authors attribute the protective effect of uric acid on the skeleton to the antioxidant properties of normal levels of uric acid (Pirro et al. 2017). On the other hand, De Pergola et al. (2017) observed that the association between serum uric acid and BMD (mostly in the femur in postmenopausal women) is partly explained by the confounding effect of adiposity, the role of which remains to be further analyzed.

\section{Chronic obstructive pulmonary disease (COPD) and bone health}

Osteoporosis occurs more frequently in patients with COPD than in the rest of the population. Female smokers are the highest risk group. In smokers, according to Bon et al. (2011), radiographic emphysema is a strong, independent predictor of low BMD. Later authors assessed cancellous and cortical bone mineralization density distribution in a small group of postmenopausal smokers. The frequency of osteoporotic fractures increased depending on the stage of the disease and mostly correlated with parameters of functional lung examination. Osteoporotics with moderately advanced disease (CT II) had higher residual lung volume than patients without osteoporosis expressed as a percentage of total pulmonary capacity (RV\% TLC) (Graat-Verboom et al. 2012). In a group of 85 patients with COPD, compressive fractures were found in $35 \%$ of patients, where the number of fractures strongly correlated with the vital lung capacity and with forced expiratory volume (FEV/1 s) (Szymanski et al. 2002). Compressive fractures of the vertebrae further aggravate pulmonary ventilation and lead to acute exacerbations of COPD. The frequency of these exacerbations is (in addition to $\mathrm{PaO}_{2}$ ) an independent predictor of a decrease in bone density. The primary cause of skeletal involvement in COPD is ventilator disorder and a high frequency of acute inflammatory exacerbations of the disease. Pathogenesis of osteopenia in COPD is complex. Significant associated factors are nicotine, reduced mobility and the loss of muscle mass, respiratory acidosis and systemic inflammation with a negative influence of interleukins and pre-existing osteopenia. Also, administration of glucocorticoids, negatively affects the skeleton (Sanel et al. 2016). Key factor in accelerating bone loss in COPD is vitamin D deficiency. Thus, fracture prevention in COPD is based on anti-inflammatory treatment, supplementation of vitamin $\mathrm{D}$, rehabilitation, and permanent monitoring of bone density.

Caffarelli et al. (2016) followed osteoporosis in 58 patients with idiopathic pulmonary fibrosis, where correlation between $\mathrm{BMD}$ in the femoral region and respiratory parameters were found, at first between BMD and $\mathrm{FVC} \%$ or DLCO \%. Vertebral fractures usually lead to worsening of respiratory parameters in these patients.

\section{Cardiovascular diseases associated with osteoporosis}

\section{Chronic heart failure (CHF)}

Fractures complicating cardiac failure are relatively frequent. Mazziotti et al. (2012) reported in patients with chronic heart failure a prevalence of thoracic vertebral fractures $-31 \%$. Leistner et al. (2012) assume that the molecular basis of accelerated loss of bone mass in cardiac patients is the activation of RANKL. In a group of 153 people (123 of whom suffered from chronic heart failure), a subgroup of cardiac patients had higher RANKL/osteoprotegerin ratios. The authors, using multivariate regression analysis, found, that the independent predictors of the RANKL level were the duration and severity of heart failure. Thus, it appears that bone catabolism is almost inevitably associated with CHF. In CHF, many other factors that predispose to the origin of osteoporosis, affect the skeleton: older age, vitamin D deficiency and hyperparathyroidism, oxidative stress, decreased kidney function, the high activity of the 
renin-angiotensin-aldosterone system, often diabetes mellitus and frailty syndrome. For the prevention of osteoporosis in cardiac patients, thiazide diuretics and spironolactone should be preferred to the loop diuretics that increase urinary calcium loss. Attention should be paid to the treatment of osteoporosis in cardiac patients, particularly because the fractures increase their mortality.

\section{Other cardiovascular diseases and osteoporosis}

Veronese et al. (2017) in a meta-analysis of 28 studies with more than 1 million participants found a small, but significantly increased risk of cardiovascular disease, such as coronary artery disease and cerebrovascular accident in subjects with low BMD. Krynytska et al. (2017) in 33 men with coronary heart disease found structural and functional changes of bone tissue in the lumbar spine in $49.2 \%$ of patients complicated by stage II-A chronic heart failure. Osteoporosis was found in $16.9 \%$ of patients. The association between the skeleton and vascular system could be explained by biological links between the RANKL/RANK/OPG axis and Wnt/ $\beta$-catenin signaling working in both systems. In other words, a key role in the association is most probably played by both osteoprotegerin and sclerostin (Karajewska-Wlodarczyk 2017). Further large studies on this topic are needed.

Calcification processes as a potential cause of osteopenia/osteoporosis

Osteoporosis is very often associated with increased calcification of the abdominal aorta and carotids. Calcified plaques were significantly correlated with osteoporosis. Low doses of supplements do not seem to influence vascular calcifications (Lampropoulos et al. 2016). Negative bone remodeling in patients with vascular calcification is probably a consequence of reduced bone formation without activation of OPG-RANKL axis (Pennisi et al. 2004).

According to some authors, osteoporosis often complicates calcium urolithiasis (Lampropoulos et al. 2016). $20 \%$ of calcium stone formers have osteopenia and $7 \%$ osteoporosis. Although normal DXA declines with increasing age, osteoporosis is more prevalent and more pronounced in older patients (over 60 years of age) with nephrolithiasis (Bijelic et al. 2016). On the other hand, Sakhaee et al. (2017) did not find any association between urine calcium and BMD in patients with calcium nephrolithiasis in a large group of males and estrogen treated females. Thus, the authors presume that mechanisms other than hypercalciuria cause osteoporosis in kidney stone formers.

\section{Cirrhosis of the liver and/or chronic hepatitis}

Complication of cirrhosis with osteoporosis is very common (50\%), in chronic active hepatitis $9.1 \%$ (Bedimo et al. 2016). Fractures are often two fold in patients with chronic liver disease (Handzlik-Orlik et al. (2016). It occurs especially in the final stage of the disease or early after liver transplantation. The toxic effects of high levels of bilirubin and bile acids to osteoblasts, which leads to a slowing of the formation of new bone, is amplified by the direct influence of alcohol (Gonzalez-Calvin 1993). The key pathogenetic factors leading to bone loss are decreased production of 25-OH vitamin $\mathrm{D}$, hypovitaminosis $\mathrm{K}$ and low levels of IGF-1 and overproduction of interleukin-1 and interleukin-6 (which activate RANKL) (Handzlik-Orlik et al. 2016). Suboptimal serum vitamin $D$ is frequently observed in HIV/AIDS patients treated with anti-retroviral pharmaceuticals (Mastaglia et al. 2017). Epidemiologic studies suggested a three-fold increased fracture incidence in patients coinfected with HIV/hepatitis $\mathrm{C}$ virus even before development of cirrhosis (Bedimo et al. 2016, Weitzmann et al. 2016) (see below).

Hepatic osteodystrophy is present in about $15-52 \%$ of cases of primary biliary cirrhosis, which depends on the severity and duration of the disease and degree of cholestasis (Glass and $\mathrm{Su} 2016$ ). According to Handzlik- Orlik et al. (2016), activated bone remodeling could be normalized by inhibitors of bone turnover, or by liver transplantation. Patients with chronic biliary cirrhosis usually slow the metabolism of cholecalciferol to the active metabolites of vitamin D. They initially may have normal DXA values, but the bone density measured by peripheral quantitative computed tomography (pQCT) usually indicates an early decrease in geometric and volumetric parameters in both cortical and trabecular bone. Upala et al. (2017) published a meta-analysis of the association between non-alcoholic fatty liver disease and BMD. Other meta-analysis involving 1,276 participants, of whom 638 had non-alcoholic fatty liver disease, showed no significant difference in BMD between subjects with fatty liver disease and controls. Due to a certain controversies, further clinical studies are required. The basic therapeutic approach in osteoporotic subjects with cirrhosis of the liver or chronic hepatitis is to optimize the nutrition and supplementation of calcium and active metabolites of vitamin D. 
The role of chronic infections with $\mathrm{HIV}, \mathrm{HCV}$ or $\mathrm{HBV}$ in development of osteopenia/osteoporosis

Fracture risk increases mainly in elderly patients with untreated chronic hepatitis induced by long-term infection due to accelerated bone resorption (increased activation of RANKL) and deterioration of bone microstructure. Moreover, in hepatitis B and hepatitis C infected subjects a crosstalk between virus activity and the patient's immune system has been observed (Biver $e t$ al. 2017). Lower serum IGF-1 and IGFBP-3 have been found in subjects with osteoporosis of the proximal femur complicating hepatitis $\mathrm{C}$ infection than in those without osteoporosis (Raslan et al. 2010). Furthermore, bone metabolism in infected patients treated with antiretroviral pharmaceuticals is additionally deteriorated by suboptimal serum vitamin D (Mastaglia et al. 2017). Unfortunately, antiviral pharmaceuticals (anti HBV and anti HIV) themselves may also be toxic to the skeleton. Thus, the harmful effect of virus infection on bone appears to be very complex (Biver et al. 2017).

\section{Chronic renal failure}

Hemodialyzed patients with vertebral fractures have significantly reduced BMD and usually reduced trabecular bone score (TBS) compared to those without fractures (Yavropoulou et al. 2017). Brunerova et al. (2016) found normal TBS only in $1 / 3$ of patients in a group of 59 patients treated with hemofiltration. Low BMD and high risk of vertebral fractures were also observed in a major study of postmenopausal women with mild renal dysfunction (Kaji et al. 2010). Nevertheless, renal osteopathy is a very serious separate chapter that goes beyond the scope of this article. Here it is worth mentioning the causal effect of not too much frequent renal tubular acidosis (RTA) on bone homeostasis. A significant proportion of patients with osteopenia or osteoporosis had incomplete RTA I. The furosemide test in this inborn disease is able to suggest a defect in $\mathrm{H}^{+}$ATPase or $\mathrm{Na}^{+}$reabsorption in the cortical collecting tubules (Weger et al. 2000). The precise detrimental effect of RTA I on bone mass remains to be identified.

\section{Further selected states complicated with osteoporosis}

\section{Frailty syndrome}

Conditions associated with frailty are muscle atrophy, low strength, falls and fractures markedly increasing mortality and morbidity (Suh and Lyles 2003).
Frailty syndrome also belongs to a group of diseases which include anorexia nervosa, neoplasias, sarcopenia, dialysis patients, all of which are endangered by fractures (Gielen et al. 2017).

\section{Beta-thalassemia and sickle cell anemia}

Osteoporosis complicates beta-thalassemia major, similar to sickle cell hemolytic anemia (mutations in the beta globin genes), which synthesizes abnormal hemoglobin S. Bone demineralization was detected in nearly $93 \%$ of these patients, mainly at the femur (Baldini et al. 2010). Pathophysiological significance in osteoporosis induced by thalassemia is most probably multifactorial, partly attributed to severe growth hormone deficiency (measured in $27.9 \%$ of subjects using GHRH plus arginine analysis. IGF-I (but not IGF-II) was low in $86.3 \%$ of thalassemic patients (Scacchi et al. 2016). No correlations were found between growth hormone peak and osteocalcin and/or telopeptides. In the case of sickle cell disease osteoporosis develops in the context of nutrient deficits, including vitamin D. Effectivity of treatment with vitamin $\mathrm{D}$, has not been extensively studied (Soe et al. 2017).

\section{Conclusion}

Osteoporosis in chronic diseases is very frequent and pathogenetically varied. It complicates the course of the underlying disease by the occurrence of fractures, which aggravate the quality of life and increase the mortality of patients from the underlying disease. This report deals with the most common and, from the point of osteoporosis, the most risky diseases. However, accelerated bone loss with fracture risk may accompany a number of other serious diseases. The secondary deterioration of bone quality in chronic diseases, such as type 2 diabetes, chronic kidney disease and chronic obstructive pulmonary disease and a number of metabolic and inflammatory disorders - are mostly associated with structural changes to collagen, altered bone turnover, increased cortical porosity and damage to the trabecular and cortical microarchitecture (Yamaguchi 2016). Accelerated bone loss with fracture risk may be accompanied by other states, such as chronic pancreatitis, cystic fibrosis and/or neurological disorder. The Global Longitudinal Study of Osteoporosis in Women (GLOW), conducted in over 52,000 subjects, has shown strong associations between fracture risk and Parkinson's disease (Ishizaki et al. 1993). At increased risk for osteoporosis 
are adults with cerebral palsy. From the point of prevention of bone loss in neurological diseases, Whitney et al. (2018) emphasize importance to maintain musculoskeletal mass and function during the lifespan.

A frequent mechanism leading to deterioration of bone mass in some states, such as diabetes mellitus, atherosclerosis, menopause or chronic kidney diseases and life style diseases (including sleep habits) may be oxidative stress (Notsu and Yamaguchi 2013, Sasaki et al. 2016). Osteoporosis in women with breast cancer associated with ovarian suppression and chemotherapy treatment and the disease alone, due to tissue infiltration or metastatic processes could also be mentioned here (Biarese et al. 1996).

A consideration of all comorbidities could predict the risk of fractures and early prevention of osteoporosis, which consists in the compensation the underlying disease (treatment of inflammation, metabolic or hormonal disorders), in the adjustment of nutritional deficiency, supplementation of vitamin D and calcium and correction of homeostasis of trace elements (Zofkova et al. 2017), as well as the rehabilitation of physical activity. Anti-resorptive therapy (using bisphosphonates, denosumab, raloxifene), or administration of teriparatide is indicated in the cases of manifest secondary osteoporosis. For inborn diseases, such as celiac disease and phenylketonuria, specific procedures are recommended for the prevention of low peak bone mass and subsequent osteoporosis in adulthood.

\section{Conflict of Interest}

There is no conflict of interest.

\section{Acknowledgements}

This work was supported by the project (Ministry of Health, Czech Republic), for conceptual development of research organization 00023761 (Institute of Endocrinology, Prague, Czech Republic).

\section{References}

ABADIE V, SOLLID LM, BARREIRO LB, JABRI B: Integration of genetic and immunological insights into a model of celiac disease pathogenesis. Annu Rev Immunol 29: 493-525, 2011.

AKOBENG AK, THOMAS AG: Systematic review: tolerable amount of gluten for people with coeliac disease. Aliment Pharmacol Ther 27: 1044-1052, 2008.

AYUS JC, FUENTES NA, NEGRI AL, MORITZ ML, GLUNTA DH, KALANTAR-ZADEH K, NIGWEKAR SU, THADHANI RI, GO AS, DE GUIROS FG: Mild prologed chronic hyponatremia and risk of hip fracture in the elderly. Nephrol Dial Transplant 31: 1662-1669, 2016.

BALDINI M, FORTI S, MARCON A, ULIVIERI FM, ORSATTI A, TAMPIERI B, AIRAGHI L, ZANABONI L, CAPPELLINI MD: Endocrine and bone disease in appropriately treated adult patients with beta-thalassemia major. Ann Hematol 89: 1207-1213, 2010.

BARAKE M, ARABI A, NAKHOUL N, EL-HAJJ FULEIHAN G, EL GHANDOUR S, KLIBANSKI A, TRITOS NA: Effects of growth hormone therapy on bone density and fracture risk in age-related osteoporosis in the absence of growth hormone deficiency: a systemic review and meta-analysis. Endocrine 59: 39-49, 2017.

BASTOS CM, ARAÚJO IM, NOGUEIRA-BARBAROSA MH, SALMON CEG, DE PAULA FJA, TRONCON LEA: Reduced bone mass and preserved marrow adipose tissue in patients with inflammatory bowel diseases in long-term remission. Osteoporos Int 28: 2167-2176, 2017.

BEDIMO R, MAALOUF NM, LO RE V 3RD: Hepatitis C virus coinfection as a risk factor for osteoporosis and fracture. Curr Opin HIV AIDS 11: 285-293, 2016.

BELSING TZ, TOFTENG C, LANDGDAHL BL, CHARLES P, FELDT-RASMUSSEN U: Can bone loss be reversed by antithyroid drug therapy in postmenopausal women with Graves' disease? Nutr Metab (Lond) 7: 72, 2010.

BIANCHI ML, BARDELLA MT: Bone in celiac disease. Osteoporos Int 19: 1705-1716, 2008.

BIARESE V, RAVIOLO P, CESARANI F, LOBETTI L: Systemic mastocytosis: a case with diffuse bone involvement. Minerva Med 87: 33-39, 1996.

BIJELIC R, MILICEVIC S, BALABAN J: Correlation of osteoporosis and calcium urolithiasis in adult population. Med Arch 70: 66-68, 2016.

BIEWENGA M, MATAWLIE RHS, FRIESEMA ECH, KOOLE-LESUIS H, LANGEVELD M, WILSON JHP, LANGENDONK JG: Osteoporosis in patients with erythropoietic protoporphyria. Br J Dermatol 177: 1693$1698,2017$. 
BIVER E, CALMY A, RIZZOLI R: Bone health in HIV and hepatitis B or C infections. Ther Adv Musculoscelet Dis 9: 22-34, 2017.

BON J, FUHRMAN CR, WEISSFELD JL, DUNCAN SR, BRANCH RA, CHANG CC, ZHANG Y, LEADER JK, GUR D, GREENSPAN SL, SCIURBA FC: Radiographic emphysema predicts low bone mineral density in a tobacco-exposed cohort. Am J Respir Crit Care Med 183: 885-890, 2011.

BOTUSHANOV NP, ORBETZOVA MM: Bone mineral density and fracture risk in patients with type 1 and type 2 diabetes mellitus. Folia Med (Plovdiv) 51: 12-17, 2009.

BRAUN T, SCHETT G: Pathways for bone loss in inflammatory disease. Curr Osteoporos Rep 10: 101-108, 2012.

BRIANI C, SAMAROO D, ALAEDINI A: Celiac disease: from gluten to autoimmunity. Autoimmun Rev 7: 644-650, 2008.

BRIOT K, GEUSENS P, EM BULTINK I, LEMS WF, ROUX C: Inflammatory diseases and bone fragility. Osteoporos Int: 28: 3301-3314, 2017.

BRUNEROVA L, RONOVA P, VERESOVA J, BERANOVA P, POTOEKOVA J, KASALICKY P, RYCHLIK I: Osteoporosis and impaired trabecular bone score in hemodialysis patients. Kidney Blood Press Res 41: 345-354, 2016.

BURNHAM JM: Inflammatory diseases and bone health in children. Curr Opin Rheumatol 24: 548-553, 2012.

CAFFARELLI C, GONNELLI S, TOMAI PITINCA MD, FRANCOLINI V, FUI A, BARGAGLI E, REFINI RM, BENNETT D, NUTI R, ROTTOLI P: Idiopathic pulmonary fibrosis a rare disease with severe bone fragility. Intern Emerg Med 11: 1087-1094, 2016.

CASHMAN KD: Altered bone metabolism in inflammatory disease: role of nutrition. Proc Nutr Soc 67: 196-205, 2008.

CHEN Z, ZHAO GH, ZHANG YK, SHEN GS, YU YJ, XU NW: Research on the correlation of diabetes mellitus complicated with osteoporosis with lipid metabolism, adipokines and inflammatory factors and its regression analysis. Eur Rev Med Pharmacol Sci 21: 3900-3905, 2017.

CHOUKAIR D, KNEPPO C, FENEBERG R, SCHÖNAU E, LINDNER M, KÖLKER S, HOFFMANN GF, TÖNSHOFF B: Analysis of the functional muscle - bone unit of the forearm in patients with phenylketonuria by peripheral quantitative computed tomography. J Inherit Metab Dis 40: 219-226, 2017.

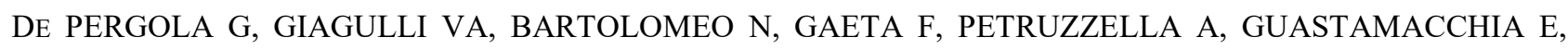
TRIGGIANI V, SILVESTRIS F: Independent relationship between serum osteocalcin and uric acid in a cohort of apparently healthy obese subjects. Endocr Metab Immune Disord Drug Targets 17: 207-212, 2017.

DIELI-CRIMI R, CÉNIT MC, NÚŇEZ C: The genetics of celiac disease: a comprehensive review of clinical implications. J Autoimmune 64: 26-41, 2015.

DOUDA T: Topical possibilities of biological therapy of idiopathic inflammation intestinal diseases - editorial (in Czech). Vnitr Lek 64: 229-231, 2018.

DUMIC-CULE I, DRACA N, LUETIC AT, JEZEK D, ROGIC D, GRGUREVIC L, VUKICEVIC S: TSH prevents bone resorption and with calcitriol synergistically stimulates bone formation in rats with low levels calciotropic hormones. Hor Metab Res 46: 305-312, 2014.

DUONG LE T, LEUNG AT, LANGDAHL B: Cathepsin $\mathrm{K}$ inhibition: a new mechanism for the treatment of osteoporosis. Calcif Tissue Int 98: 381-397, 2016.

EDENS C, ROBINSON AB: Systemic lupus erythematosus, bone health, and osteoporosis. Curr Opin Endocrinol Diabetes Obes 22: 422-431, 2015.

GIELEN E, BERGMANN P, BRUYERE O, CAVALIER E, DELANAYE P, GOEMAERE S, KAUFMAN JM, LOCQUET MR, REGINSTER JY, ROZENBERG S, VANDENBROUCKE AM, BODY JJ: Osteoporosis in frail patients: a consensus paper of the Belgian Bone Club. Calcif Tissue Int 101: 111-131, 2017.

GLASS LM, SU GL: Metabolic bone disease in primary biliary cirrhosis. Gastrointestinal Clin North Am 45: 333-343, 2016.

GONZALEZ-CALVIN JL, GARCIA-SANCHEZ A, BELLOT V, MUŇOZ-TORRES M, RAYA-ALVAREZ E, SALVATIERRA-RIOS D: Mineral metabolism, osteoblastic function and bone mass in chronic alcoholism. Alcohol Alcohol 28: 571-579, 1993. 
GRAAT-VERBOOM L, SMEENK FW, VAN DEN BORNE BE, SPRUIT MA, DONKERS-VAN ROSSUM AB, AARTS RP, WOUTERS EF: Risk factors for osteoporosis in Caucasian patients with moderate chronic obstructive pulmonary disease: a case control study. Bone 50: 1234-1239, 2012.

HANDZLIK-ORLIK G, HOLECKI M, WICZYNSKI K, DULAWA J: Osteoporosis in liver disease: pathogenesis and management. Ther Adv Endocrinol Metab 7: 128-135, 2016.

HERNANDEZ L, GREEN PH: Extraintestinal manifestations of celiac disease. Curr Gastroenterol Rep 8: 383-389, 2006.

HOCHULI M, BOLLHALDER S, THIERER C, REFARDT J, GERBER P, BAUMGARTNER MR: Effects of inadequate amino acid mixture intake of nutrient supply of adult patients with phenylketonuria. Ann Nutr Metab 71: 129-135, 2017.

HODGSON SF, DICKSON ER, EASTELL R, ERIKSEN EF, BRYANT SC, RIGGS BL: Rates of cancellous bone remodeling and turnover in osteopenia associated with primary biliary cirrhosis. Bone 14: 819-827, 1993.

HUSSIEN YM, SHEHATA A, KARAM RA, ALZAHRANI SS, MAGDY H, EL-SHAFEY AM: Polymorphism in vitamin D receptor and osteoprotegerin genes in Egyptian rheumatoid arthritis patients with and without osteoporosis. Mol Biol Rep 40: 3675-3680, 2013.

ISHIZAKI F, HARADA T, KATAYAMA S, ABE H, NAKAMURA S: Bone changes in Parkinson's disease (in Japanese). No To Shinkei 45: 719-724, 1993.

JUNEAU CR, FRANASIAK JM, GOODMAN LR, MARIN D, SCOTT K, MORIN SJ, NEAL SA, JUNEAU JE, SCOTT RT: Celiac disease is not more prevalent in patients undergoing in vitro fertilization and does not affect reproductive outcome with or without treatment: a large prospective cohort study. Fertil Steril 110: 437-442, 2018.

KAJI H, YAMAGUCHI M, YAMAGUCHI T, SHIGEMATSU T, SUGIMOTO T: Mild renal dysfunction is a risk factor for a decrease in bone mineral density and vertebral fractures in Japanese postmenopausal women. J Clin Endocrinol Metab 95: 4635-4642, 2010.

KARHUS LL, THUESEN BH, SKAABY T, RUMESSEN JJ, LINNEBERG A: The distribution of HLA DQ2 and DQ8 haplotypes and their association with health indicators in a general Danish population. United European Gastroenterol J 6: 866-878, 2018.

KHALEGHI S, JU JM, LAMBA A, MURRAY JA: The potential utility of tight junction regulation in celiac disease: focus on larazotide acetate. Therapy Adv Gastroenterol 9: 37-49, 2016.

KIYOKAWA H, MURO S, OGUMA T, SATO S, TANABE N, TAKAHASHI T, KUDO M, KINOSE D, KONDOH H, KUBO T, HOSHINO Y, OGAWA E, HIRAI T, MISHIMA M: Impact of COPD exacerbations on osteoporosis assessed by chest CT scan. COPD 9: 235-242, 2012.

KRELA-KAŹMIERCZAK I, SZYMCZAK A, LYKOWSKA-SZUBER L, EDER P, LINKE K: Osteoporosis in gastrointestinal diseases Adv Clin Exp Med 25: 185-190, 2016.

KRYNYTSKA I, MARUSHCHAK M, ZAETS T, SAVCHENKO I, HABOR H: Investigation of bone mineralization in patients with coronary heart disease complicated by chronic heart failure, stage II-A. Georgian Med News 267: 43-48, 2017.

KULL M, KALLIKORM R, LEMBER M: Impact of molecularly defined hypolactasia, self- perceived milk intolerance and milk consumption on bone mineral density in a population sample in Northern Europe. Scand $J$ Gastroentarol 44: 415-421, 2009.

LAMPROPOULOS CE, KALAMARA P, KONSTA M, PAPAIOANNOU I, PAPADIMA E, ANTONIOU Z, ANDRIANOPOULOU A, VLACHOYIANNOPOULOS PG: Osteoporosis and vascular calcification in postmenopausal women. Climacteric 19: 303-307, 2016.

LEISTNER DM, SEEGER FH, FISCHER A, RÖXE T, KLOTSCHE J, IEKUSHI K, SEEGER T, ASSMUS B, HONOLD J, KARAKAS M, BADENHOOP K, FRANTZ S, DIMMELER S, ZEIHER AM: Elevated levels of the mediator of catabolic bone remodeling RANKL in the bone marrow environment link chronic heart failure with osteoporosis. Circ Heart Fail 5: 769-777, 2012.

LEWANDOWSKA K, CIEPIELA O, SZYPOWSKA A, WYHOWSKI J, GLODKOWSKA- MRÓWKA E, POPKO K, OSLAFIN M, PYRZAK B, DEMKOW U: Celiac antibodies in children with type 1 diabetes - A diagnostic validation study. Autoimmunity 51: 81-88, 2018. 
MARATOVA K, HRADSKY O, MATYSKOVA J, COPOVA I, SOUCEK O, SUMNIK Z, BRONSKY J: Musculoskeletal system in children and adolescents with inflammatory bowel disease: normal muscle force, decreased trabecular bone mineral density and low prevalence of vertebral fractures. Eur J Pediatr 176: 1355-1363, 2017.

MARTINEZ-MARTINEZ MI, ALEGRE-MARTINEZ A, GARCIA-IBANEZ J, CAULI O: Quality of life in people with coeliac disease: Psychological and social-economic aspects. Endocr Metab Immune Disord Drug Targets in press 2018. doi: 10.2174/1871530318666180723100003

MASTAGLIA S, WATSON D, BELLO N, FRIDMAN V, STECHER D, OLIVERI B: Vitamin D levels and their impact on mineral metabolism in HIV infected patients bone loss in fracture: an exploratory study. Clin Cases Miner Bone Metabol 14: 18-22, 2017.

MAZZIOTTI G, BARACCA M, DOGA M, PORCELLI T, VESCOVI PP, GIUSTINA A: Prevalence of thoracic vertebral fractures in hospitalized elderly patients with heart failure. Eur J Endocrinol 167: 865-872, 2012.

MCALLISTER BP, WILLIAMS E, CLARKE K: A comprehensive review of celiac disease/gluten-sensitive enteropathies. Clin Rev Allergy Immunol in press 2018. doi: 10.1007/s12016-018-8691-2

MENCEJ-BEDRAC S, PREZEJL J, KOCJAN T, TUCAC K, OSTANEK B, SMELCER M, MARC J: The combination of vitamin D receptor, osteoprotegerin and tumor necrosis factor superfamily member 11 genes are associated with bone mineral density. J Mol Endocrinol 42: 239-247, 2009.

MILLER PD: Denosumab: anti-RANKL antibody. Curr Osteoporos Rep 7: 18-22, 2009.

MODAN-MOSES D, VERED I, SCHWARTZ G, ANIKSTER Y, ABRAHAM S, SEGEV R, EFRATI O: Peak bone mass in patients with phenylketonuria. J Inherit Metab Dis 30: 202-208, 2007.

MONTAGNANI A, GONNELLI S, ALESSANDRI M, NUTI R: Osteoporosis and risk of fracture in patients with diabetes: an update. Aging Clin Exp Res 23: 84-90, 2011.

MYSLIWIEC J, ZBUCKI R, NIKOLAJUK A, MYSLIWIEC P, KAMINSKI K, BONDYRA Z, DADAN J, GORSKA M, WINICKA MM: Estrogens modulate RANKL-RANK/osteoprotegerin mediated interleukin- 6 effect on thyrotoxicosis-related bone turnover in mice. Horm Metab Res 43: 236-240, 2011.

NOTSU M, YAMAGUCHI T: Secondary osteoporosis or secondary contributors to bone loss in fracture. Effect of oxidative stress on bone metabolism. Clin Calcium 23: 1285-1292, 2013.

PIRRO M, MANNARINOMR, BIACONI V, DE VUONO S, SHAHEBKAR A, BEGAGLIA F, FRANCESCHINI L, SCARPONI AM, MANNARINO E, MERRIMAN T: Uric acid and bone mineral in postmenopausal osteoporotic women: the link lies within the fat. Osteoporos Int 28: 973-981, 2017.

RASLAN HM, ELHOSARY Y, EZZAT WM, RASHEED EA, RASHEED MA: Potential role of insulin-like growth factor 1, insulin-like growth factor binding protein 3 and bone mineral density in patients with chronic hepatitis C virus in Cairo, Egypt. Trans R Trop Med Hyg 104: 429-432, 2010.

SAKHAEE K, MAALOUF NM, POINDEXTER J, ADAMS-HUET B, MOE OW: Relationship between urinary calcium and bone mineral density in patients with calcium nephrolithiasis. J Urol 197: 1472-1477, 2017.

SAMADI A, GURLEK A, SENDUR SN, KARAHAN S, AKBIYIK F, LAY I: Oxysterol species: reliable markers of oxidative stress in diabetes mellitus. $J$ Endocrinol Invest in press 2018. doi: 10.1007/s40618-018-0873-5

SANEL S, SEZGIN G, SARIMAN N, UGUTMEN E, SOLAKOGLU C: Bilateral non-traumatic hip fractures in a heavy smoker COPD patient on inhaled steroids. Arch Osteoporos 11: 8, 2016.

SASAKI N, FUJIWARA S, YAMASHITA H, OZONO R, TERAMEN K, KIHARA Y: Impact of sleep on osteoporosis: sleep quality is associated with bone stiffness index. Sleep Med 25: 73-77, 2016.

SCHETT G: Autoimmunity as a trigger for structural bone damage in rheumatoid arthritis. Mod Rheumatol 27: 193-197, 2017.

SCACCHI M, DANESI L, CATTANEO A, SCIORTINO G, RADIN R, AMBROGIO AG, VITALE G, D'ANGELO E, MIRRA N, ZANABONI L, ARVIGO M, BOSCHETTI M, FERONE D, MARZULLO P, BALDINI M, CASSINERIO E, CAPPELLINI MD, PERSANI L, CAVAGNINI F: Bone turnover and mineral density in adult thalassemic patients: relationship with growth hormone secretory status and circulating somatomedins. Endocrine 53: 551-557, 2016.

STAZI AV, TRECCA A, TRINTI B: Osteoporosis in celiac disease and in endocrine and reproductive disorders. World J Gastroenterol 14: 498-505, 2008. 
STRAUB RH, CUTOLO M, PACIFICI R: Evolutionary medicine and bone loss in chronic inflammatory diseases theory of inflammation-related osteopenia. Semin Arthritis Rheum 45: 220-228, 2015.

SUMAILY AM, MUJAMAMMI AH: Phenylketonuria: a new look at an old topic, advances in laboratory diagnosis, and therapeutic strategies. Int J Health Sci (Oassim) 11: 63-70, 2017.

SUMÁNSZKI C, BARTA AG, REISMANN P: Adult phenylketonuria (in Hungarian). Orv Hetil 158: 1868-1872, 2017.

SZAMOSI S, HORVÁTH A, SZEKANECZ Z, SZÜCS G: Vitamin D metabolism and osteoporosis in systemic sclerosis. Orv Hetil 158: 1252-1258, 2017.

TARIQ S, TARIQ S, LONE KP: Interplay of vitamin D, vitamin B12, homocysteine and bone mineral density in postmenopausal females. Health Care Women Int in press 2018. doi: 10.1080/07399332.2018.1444042

UPALA S, JARUVONGVANICH V, WIJARNPREECHA K, SANGUANKEO A: Nonalcoholic fatty liver disease and osteoporosis: a systematic review and meta-analysis. J Bone Miner Metab 35: 685-693, 2017.

VAN SPRONSEN FJ, ENNS GM: Future treatment strategies in phenylketonuria. Mol Genet Metab 99 (Suppl 1): S90-S95, 2010.

VAN WEGBERG AMJ, MACDONALD A, AHRING K, BÉLANGER-QUINTANA A, BLAU N, BOSCH AM, BURLINA A, CAMPISTOL J, FEILLET F, GIŽEWSKA M, HUIJBREGTS SC, KEARNEY S, LEUZZI V, MAILLOT F, MUNTAU AC, VAN RIJN M, TREFZ F, WALTER JH, VAN SPRONSEN FJ: The complete European guidelines on phenylketonuria: diagnosis and treatment. Orphanet J Rare Dis 12: 162, 2017.

VERDU EF, DANSKA JS: Common ground: shared risk factors for type 1 diabetes and celiac disease. Nat Immunol 19: 685-695, 2018.

VERONESE N, STUBBS B, CREPALDI G, SOLMI M, COOPER C, HARVEY NC, REGINSTER JY, RIZZOLI R, CIVITELLI RE, SCHOFFIELD P, MAGGI S, LAMB SE: Relationship between low bone mineral density and fractures with incident cardiovascular disease: a systemic review and meta-analysis. $J$ Bone Miner Res 32: 1126-1135, 2017.

VOKÓ Z, GÁSPÁR K, INOTAI A, HORVÁTH C, BORS K, SPEER G, KALÓ Z: Osteoporotic fractures may impair life as much as the complications of diabetes. J Eval Clin Pract 23: 1375-1380, 2017.

WEGER W, KOTANKO P, WEGER M, DEUTSCHMANN H, SKRABAL F: Prevalence and characterization of renal tubular acidosis in patients with osteopenia and osteoporosis and in non-porotic controls. Nephrol Dial Transplant 15: 975-980, 2000.

WHITNEY DG, HURVITZ EA, DEVLIN MJ, CAIRD MS, FRENCH ZP, ELLENBERG EC, PETERSON MD: Age trajectories of musculoskeletal morbidities in adults with cerebral palsy. Bone 114: 285-291, 2018.

WEITZMANN MN, OFOTOKUN I, TITANJI K, SHARMA A, YIN MT: Bone loss among women living with HIV. Curr HIV/AIDS Rep 13: 367-373, 2016.

YAMAGUCHI M: The assessment of bone quality in lifestyle-related diseases. Clin Calcium 26: 65-72, 2016.

YAVROPOULOU MP, VAIOS V, PIKILIDOU M, CHRYSSOGONIDIS I, SACHINIDOU M, TOURNIS S, MAKRIS K, KOTSA K, DANIILIDIS M, HARITANTI A, LIAKOPOULOS V: Bone quality assessment as measured by trabecular bone score in patients with end-stage renal disease on dialysis. $J$ Clin Densitom 20: 490-497, 2017.

ZHANG W, ZHANG Y, LIU Y, WANG J, GAO L, YU C, YAN H, ZHAO J, XU J: Thyroid-stimulating hormone maintains bone mass and strength by suppressing osteoclast differentiation. J Biomech 47: 1307-1314, 2014.

ZOFKOVA I: Bone tissue as a systemic endocrine regulator. Physiol Res 64: 439-445, 2015.

ZOFKOVA I, HILL M: Biochemical markers of bone remodeling correlate negatively with circulating TSH in postmenopausal women. Endocr Regul 42: 121-127, 2008.

ZOFKOVA I, DAVIS M, BLAHOS J: Trace elements have beneficial, as well as detrimental effects on bone homeostasis. Physiol Res 66: 391-402, 2017. 